\title{
$P$-Hydroxycinnamaldehyde Induces B16-F1 Melanoma Cell Differentiation via the RhoA-MAPK Signaling Pathway
}

\author{
Lian-mei Zhao Guo-gui Sun ${ }^{\mathrm{b}}$ Li-na Han ${ }^{\mathrm{a}}$ Li-hua Liuc Feng-zhi Ren ${ }^{\mathrm{d}}$ Lei Lia \\ Ming Maa Bao-en Shan ${ }^{a}$ \\ aResearch centre, 'Department of Biotherapy, the Fourth Hospital of Hebei Medical University, \\ Shijiazhuang, bDepartment of tumor research institute, Tangshan people's hospital, Tangshan, \\ dNew Drug Research and Development Centre of North China Pharmaceutical Group Corporation, \\ Shijiazhuang, China
}

\section{Key Words}

$P$-hydroxycinnamaldehyde $\cdot$ Melanoma $\cdot$ Differentiation $・$ MAPK $・$ GTP-RhoA

\begin{abstract}
Background/Aims: Due to its antitumor and gastroprotective properties, cochinchina momordica seed (CMS), has been widely used to treat cancer patients in Asia. Our previous reports have shown that CMS is able to induce the differentiation of B16-F1 melanoma cells. However, its functional component and mechanism remain unclear and are addressed in this study. Methods and Results: CMSP ( $p$-hydroxycinnamaldehyde isolated from CMS) inhibited the proliferation, migration and invasiveness of B16-F1 cells both in vivo and in vitro. CMSP also induced the differentiation of B16-F1 cells, as characterized by dendrite-like outgrowth, increased melanogenesis and enhanced tyrosinase activity. Furthermore, CMSP treatment reduced the level of malignant markers of melanoma, specifically S-100B and melanomaderived growth regulatory protein precursor (MIA), in a concentration-dependent manner. According to a western blot analysis, B16-F1 cells treated with CMSP exhibited a sustained increase in p-P38 and decreased activities of ERK and JNK. Our data further indicated that the downregulation of GTP-RhoA, which was mediated by increased CAMP release, was involved in CMSP-induced changes in MAPK, while LPA (Lysophosphatidic acid) partially reversed CMSPinduced B16 cell differentiation. Conclusion: These results demonstrated that CMSP-induced differentiation of B16F1 cells may occur through the RhoA-MAPK axis, which suggests a new potential strategy for melanoma treatment.
\end{abstract}

L.-m. Zhao and G.-g. Sun contributed equally to this work.

Professor Bao-en Shan

KARGER
Research centre, the Fourth Hospital of Hebei Medical University, 12\# Jiankang road, Shijiazhuang, (China)

Tel. 86311-86095283, E-Mail shanbaoen@163.com 


\section{Cellular Physiology Cell Physiol Biochem 2016;38:2247-2260 \begin{tabular}{l|l|l}
\hline DOI: 10.1159/000445580 & (C)16 S. Karger AG, Basel
\end{tabular} and Biochemistry Published online: May 19, $2016 \quad$ www.karger.com/cpb \\ Zhao et al.: Melanoma Differentiation by $P$-Hydroxycinnamaldehyde}

\section{Introduction}

Melanoma is the deadliest form of skin cancer, and although it accounts for only $4 \%$ of skin cancer cases, it is responsible for $80 \%$ of skin cancer-related deaths [1]. The median survival time of patients with metastatic melanoma is 8-9 months, and the 3-year overall survival rate is less than 15\% [2]. Because melanomas are highly resistant to most standard treatments, there is an urgent need to identify novel and more effective therapeutic strategies for metastatic melanoma. Recently, studies on tumor cell differentiation have provided useful information for the design of cancer treatments. Many recent reports have shown that the dendritic outgrowth of melanocytes or melanoma cells was promoted by cAMP-elevating agents, growth factors, and UV irradiation, as well as by the induction of melanogenesis [3]. Therefore, dendrites are recognized as morphological indicators of melanocyte or melanoma cell differentiation. The cAMP second messenger pathway stimulates the formation of melanocyte dendrites, as evidenced, for example, by experiments that use agents that increase cAMP levels (e.g., forskolin). Scott et al. reported that dendrite formation in B16 mouse melanoma cells was stimulated by cAMP-elevating agents, which attenuate the assembly of actin stress fibers via the inactivation of Rho, a small GTP-binding protein [4]. Several agents have been reported to induce the differentiation of melanoma cells, and these include a-melanocyte-stimulating hormone (a-MSH), which is known to elevate cAMP levels [5], lupeol [6] and forskolin [7]. However, potential drugs, especially those extracted from plants, have not been well studied for the induction of melanoma differentiation.

In the search for novel inducers of differentiation for the treatment of cancer, herbs that are currently used as traditional medicines for cancer treatment are promising candidates. Cochinchina momordica seed (CMS) is the dried ripe seed of Momordica cochinchinensis (Lour.) Spreng. CMS extracts have been proposed to exert cytotoxic effects via the PARP and p53 signaling pathways in human gastric cancer cells and to act as gastroprotective agents against acute gastric mucosal damage or as potential immunologic adjuvants [8-10]. CMS extracts have also been widely used to treat various cancers in China, but its mechanisms of action are unclear. As our previous study showed, an ethyl ester extract of CMS (CMSEE) was able to induce the differentiation of melanoma B16 cells via the MAPK signaling pathway [11]. In the present study, we found that the chemical compound trans-p-hydroxycinnamaldehyde, which was isolated from CMS (CMSP), was at least partly responsible for this activity. The signaling pathway that was involved in CMSP-induced B16-F1 cell differentiation was then identified.

\section{Materials and Methods}

\section{Materials}

The mouse melanoma cell line B16F1 was obtained from the Cellular Biology Institute of the Shanghai Academy of Sciences (Shanghai, China). The normal melanocytic cell line HEM- $\alpha$ was obtained from Sciencell (Carlsbad, CA, USA). Both of these cell lines were maintained in RPMI-1640 medium supplemented with $5 \%$ fetal calf serum (FCS), $100 \mathrm{U} / \mathrm{ml}$ penicillin and $100 \mu \mathrm{g} / \mathrm{ml}$ phytomycin. The cell lines were cultured at $37^{\circ} \mathrm{C}$ in a humidified atmosphere in an incubator with $5 \% \mathrm{CO}_{2}$. RPMI-1640, FCS and PBS were obtained from Gibco-BRL (Life Technologies, Paisley, Scotland). Forskolin was purchased from Sigma (Number: 120M5054V; Sigma Chemical Co., St Louis, MO, USA). LPA (lysophosphatidic acid, Number: L7260) and L-dopa (3, 4-dihydroxy-L-phenyl-alanine, Number: 049K1310) were also purchased from Sigma. The cAMP ELISA kit (K371-100) was purchased from Biovision (Bioptics, Tucson, AZ, USA). Antibodies to total p44/42 MAPK (ERK1/2), pho-p44/42 ERK1/2 (Thr202/Tyr204), total SAPK-JNK, p-JNK, p38 MAP, p-p38 MAP, and p-PKC, as well as the Active Rho Detection Kit (8820) were all purchased from Cell Signaling Technology, Inc. (CST, CA, USA); antibodies against GAPDH, Tyr, Trp1, MMP2, MMP9, MIA, and S-100B were supplied by Santa Cruz Biotechnology, Inc. (Santa Cruz, CA, USA). 


\section{Cellular Physiology Cell Physiol Biochem 2016;38:2247-2260 \begin{tabular}{l|l|l}
\hline DOI: 10.1159/000445580 & (c) 2016 S. Karger AG, Basel
\end{tabular} \begin{tabular}{l|l} 
and Biochemistry Published online: May 19, 2016 & www.karger.com/cpb
\end{tabular} \\ Zhao et al.: Melanoma Differentiation by $P$-Hydroxycinnamaldehyde}

\section{Extraction and isolation of CMSP}

CMS was purchased from Lerentang Pharmacy of Shijiazhuang (Hebei province, China) and was identified by Professor Ren (New Drug Research and Development Center of North China Pharmaceutical Group Corporation, Shijiazhuang, China). The dried CMS powder (5 kg) was extracted with $95 \%$ ethanol (2 $\times 15 \mathrm{~L}$ ) under reflux for $2 \mathrm{~h}$. The combined 95\% ethanol extracts were then concentrated under a vacuum to generate a viscous residue. The residue was suspended in water ( $3 \mathrm{~L}$ ) and was then extracted withEtOAc (Ethyl acetate, $3 \times 2 \mathrm{~L}$ ). The ethyl acetate extracts were subjected to column chromatography on a PS25300 with a successive elution system comprised of $60 \%$ acetone, $70 \%$ acetone, and $80 \%$ acetone. The $70 \%$ acetone portion ( $6.4 \mathrm{~g}$ ) was subjected to a silica gel column and was eluted with chloroform followed by chloroform-acetone at ratios of 5:1, 3:1 and 1:1. The chloroform fraction was applied to a Pre-HPLC column $\left(15 \% \mathrm{CH}_{3} \mathrm{CN}-\mathrm{H}_{2} \mathrm{O}\right.$, Phenomenex $\left.250 \times 21.2 \mathrm{~mm}, 10 \mu \mathrm{m}\right)$ to generate the $p$-hydroxycinnamaldehyde compound (termed CMSP in this study), which was verified on the basis of ESI-MS (ZMD Micromass, Micromass, England) and NMR spectroscopy (INVOA500, Varian, USA). CMSP was dissolved in DMSO at a dose of $1 \mathrm{mg} / \mathrm{ml}$ for storage so that the proportion of DMSO was $0.01 \%$. The indicated concentration of CMSP was obtained by the resolution of this compound in serum-free medium before use.

\section{Cell viability and colony formation}

The effect of CMSP on the viability of melanoma cells was determined by MTS (3-(4, 5-dimethylthiazol-2yl)-5-(3-carboxymethoxyphenyl)-2-(4-sulfophenyl)-2H-tetazolium]) assay according to the manufacturer's instructions (Promega, Madison, WI, USA). The cells were plated at a density of $1 \times 10^{4}$ cells per well in 100 $\mu \mathrm{l}$ of complete culture medium and were treated with CMSP in 96-well microtiter plates (Costar, USA). After incubation for 24,48 or $72 \mathrm{~h}$ at $37^{\circ} \mathrm{C}$ in a humidified incubator, MTS solution was added (20 $\mu \mathrm{l} /$ well) to the cells and incubated for $2 \mathrm{~h}$ at $37^{\circ} \mathrm{C}$. The absorbance at $492 \mathrm{~nm}$ was measured with a microplate reader (Titertek Multiskan, North Ryde, Australia) to assess the effect of CMSP on cell viability. For the colony forming assay, 1000 cells were seeded into $6-\mathrm{cm}$ dishes and were cultured in a humidified incubator with $5 \% \mathrm{CO}_{2}$ for 10 days. The medium was changed every 2 days. After incubation, the cell colonies were fixed in $4 \%$ paraformaldehyde for $15 \mathrm{~min}$; the colonies were then stained by the addition of $3 \mathrm{ml}$ of $2 \%$ crystal violet for 5 minutes and counted.

\section{Cell morphology and differentiation}

To evaluate the effect of CMSP on cell differentiation, $5 \times 10^{4}$ B16-F1 cells were cultured in 35-mm dishes. After treatment with different doses of CMSP for $48 \mathrm{~h}$, the cells were fixed in $4 \%$ paraformaldehyde for $30 \mathrm{~min}$ at room temperature, were stained with Giemsa ( $0.1 \%$ in glycerol and methanol) for $1 \mathrm{~min}$, and were then stained with $0.025 \%$ Giemsa staining solution for $15 \mathrm{~min}$. The cell differentiation rate was obtained as the ratio of the number of cells with cytoplasmic extensions longer than three cellular bodies to the total number of cells [11].

\section{Melanogenic content and tyrosinase activity}

Melanin release was measured as previously described [12]. Briefly, cells were incubated with different doses of CMSP or Forskolin $(10 \mu \mathrm{M})$ for $72 \mathrm{~h}$ and were then washed with PBS and dissolved in 1.0 $\mathrm{N} \mathrm{NaOH}$ for $1 \mathrm{~h}$ at $80^{\circ} \mathrm{C}$. The absorbance at $470 \mathrm{~nm}$ was measured, and the melanin content was measured by using the authentic standard of synthetic melanin. Tyrosinase activity was assayed as previously described [13] but with minor modifications. The cells were washed with ice-cold PBS and incubated at $4^{\circ} \mathrm{C}$ for 30 min in lysis buffer (10 nM SDS, $150 \mathrm{mM} \mathrm{NaCl}, 1 \mathrm{mM}$ EDTA, $0.5 \mathrm{mM}$ phenylmethylsulfonyl fluoride, and 10 $\mu \mathrm{g} / \mathrm{ml}$ leupeptin). The lysates were centrifuged at $15,000 \times \mathrm{g}$ for $30 \mathrm{~min}$ to obtain the supernatant, which was the source of tyrosinase. The reaction mixture consisted of $50 \mathrm{mM}$ phosphate buffer (pH 6.8), $0.05 \%$ L-dopa, and the supernatant (tyrosinase). After incubation at $37^{\circ} \mathrm{C}$ for $20 \mathrm{~min}$, dopachrome formation was monitored by measurement of the absorbance at a wavelength of $570 \mathrm{~nm}$.

\section{Tumor cell migration and invasion assays}

The tumor cell migration assay was performed using Boyden chambers with filter inserts (pore size, 8- $\mu \mathrm{m}$ ) (Collaborative Biomedical, Becton Dickinson Labware, Bedford, MA, USA). Briefly, after treatment with $0,10,20$ or $40 \mathrm{nM}$ CMSP for $48 \mathrm{~h}, 1 \times 10^{5}$ cells were seeded in the upper chambers and incubated in $400 \mu \mathrm{l}$ FBS-free medium, while $600 \mu \mathrm{L} 10 \%$ FBS medium was added to the lower chambers. The plates were 


\section{Cellular Physiology Cell Physiol Biochem 2016;38:2247-2260 \begin{tabular}{l|l|l} 
DOI: 10.1159/000445580 & (C) 2016 S. Karger AG, Basel
\end{tabular} and Biochemistry Published online: May 19, $2016 \quad$ www.karger.com/cpb \\ Zhao et al.: Melanoma Differentiation by $P$-Hydroxycinnamaldehyde}

then incubated for $24 \mathrm{~h}$. Cells on the upper side of the filters were removed by cotton-tipped swabs, and the filters were washed with PBS. Then, the cells on the lower side were fixed in $4 \%$ paraformaldehyde and stained with $1 \%$ crystal violet in PBS for $5 \mathrm{~min}$ at room temperature. The cells on the lower side of the filters were defined as invasive cells and were counted at $\times 200$ magnification in five random fields on each filter.

\section{Western blot analysis}

Lysates from B16F1 cells were prepared with $500 \mu \mathrm{l}$ of lysis buffer (1\% Triton X-100, $150 \mathrm{mM} \mathrm{NaCl}, 10$ mM Tris-HCl (pH 7.4), 1 mM EDTA, 1 mM EGTA (pH 8.0), $0.2 \mathrm{mM} \mathrm{Na}_{3} \mathrm{VO}_{4}, 0.2 \mathrm{mM}$ phenylmethylsulfonylfluoride, and $0.5 \% \mathrm{NP}-40$ ). The total amount of protein was evaluated by BCA assay. The protein was then subjected to SDS-PAGE using a 12\% gel and was electrotransferred to polyvinylidene difluoride (PVDF) membranes (Millipore, Bed-ford, MA, USA). The membranes were blocked with 5\% BSA for $2 \mathrm{~h}$ at room temperature and were incubated overnight at $4^{\circ} \mathrm{C}$ with the primary antibodies as described individually in the figure legends. The bound primary antibodies were detected by the appropriate fluorochrome-labeled secondary antirabbit or anti-mouse IgG (IRDye 800 (700)-LI-COR, Odyssey). After three washes in TBS-T, the membranes were imaged with an Odyssey infrared imaging system (USA, LI-COR). The levels of the protein were calculated as the ratio of the intensity of protein to that of GAPDH. Experiments were performed in triplicate wells in each run and were repeated three times.

\section{Morphology of B16F1 cells treated by CMSP as observed by TEM}

The morphologic changes of B16F1 cells were observed by transmission electron microscopy (TEM) as previously described [14]. Exponentially growing B16F1 cells were seeded in a 25- $\mathrm{cm}^{2}$ flask at a density of $1.5 \times 10^{6}$ cells per flask and were exposed to CMSP $(20 \mu \mathrm{M})$ or Forskolin $(10 \mu \mathrm{M})$ for $48 \mathrm{~h}$. The cells were fixed in $2.5 \%$ glutaraldehyde and washed with $0.075 \mathrm{M}$ phosphate buffer (pH 7.4-7.6). The cells were then fixed in $0.25 \%$ glutaraldehyde, dehydrated in increasing concentrations of ethanol $(30,50,70,90$, and $100 \%$ ) and embedded in Quetol resin. Ultra-thin sections mounted on a copper grid were contrasted with 4\% uranyl acetate and Reynolds' lead citrate. The cells were viewed with a multi-purpose Philips 301 TEM at the Electron Microscopy Unit of Hebei Medical University (Shijiazhuang, China).

cAMP Production Assay

cAMP production was detected as previously described [15]. Briefly, B16 cells were treated with 10, 20 or $40 \mu \mathrm{M}$ cAMP for 30,60 or $120 \mathrm{~min}$ and were maintained at $37^{\circ} \mathrm{C}$. The cells were lysed and separated by centrifugation, and the concentration of cAMP was detected by a direct cAMP ELISA (performed according to the kit instructions). The optical density was measured at $405 \mathrm{nM}$, and the concentration of intracellular cAMP was calculated using a weighted six parameter logistic.

\section{In vivo tumor growth assay}

C57BL/6 mice were used in this study. The mice were housed and maintained according to the National Research Council Guide for the Care and Use of Laboratory Animals, and this study was approved by the Institutional Animal Care and Use Committee (IACUC) of Hebei Medical University, Shijiazhuang, China. B16F1 melanoma cells were harvested by trypsin solution and were resuspended in PBS. Cells (1 $\times 10^{6}$ cells/mouse) in $0.1 \mathrm{ml}$ of PBS were injected subcutaneously into C57BL/ 6 mice. When the tumor size reached $40 \mathrm{~mm}^{3}$ in volume, the mice were randomly divided into the control and treatment groups, which each contained ten mice. The mice were then randomly divided into two groups (6 mice/group). Intraperitoneal injections of CMSP were administered weekly at a dose of $2 \mathrm{mg} / \mathrm{kg}$ once every 2 days for three weeks. Control animals received only saline vehicle according to an identical schedule. The tumor size was monitored twice a week by measuring the length and width with a caliper. The tumor volume was estimated using the following formula: volume $=$ width $2 \times$ length $\times 1 / 2$. The mice were sacrificed by cervical dislocation on day 25 after treatment, and the tumor, liver, spleen and lungs were removed, washed with PBS, and stained with H\&E. Immunohistochemical staining was performed to detect the expression of Tyr, MMP9, S-100B, p-P38, p-ERK and GTP-RhoA in tumor tissues.

Immunohistochemistry

Immunohistochemistry was performed according to the streptavidin-peroxidase (SP) method [16]. Formalin-fixed, paraffin-embedded tumor tissues were cut into 4-5- $\mu$ m-thick sections. The sections were 
deparaffinized and rehydrated with xylene and ethanol, respectively. Endogenous peroxidase activity was blocked with $3 \% \mathrm{H}_{2} \mathrm{O}_{2}$ in deionized water for $20 \mathrm{~min}$. After blocking with $1 \%$ goat serum, the slides were placed in Tris-EDTA buffer ( $\mathrm{pH}$ 9.0) and antigen retrieval was performed in a pressure cooker for $10 \mathrm{~min}$; the slides were then cooled to room temperature. Without washing, the sections were incubated with primary antibodies against Tyr, MMP9, S-100B, p-P38, p-ERK or GTP-RhoA overnight at $4^{\circ} \mathrm{C}$ followed by incubation with a biotinylated secondary antibody and streptavidin-biotinylated horseradish peroxidase complex (Zhongshan, Beijing, China). Protein expression was visualized and classified based on the percentage of positive cells and the intensity of staining.

\section{Statistical analysis}

Data are reported as the mean \pm the standard deviation (SD). One-way analysis of variance (ANOVA) was performed to determine whether significant differences existed among the groups. This was followed by Student's $t$-test to determine statistical significance. A P value of less than 0.05 or 0.01 was considered statistically significant, as indicated in the figures. All data analyses were performed using SPSS13.0 software (SPSS, Chicago, USA).

\section{Results}

Inhibition of B16-F1 cell proliferation by compounds isolated from an EtOAc extract of CMS

Our previous report showed that an ethyl ester (EtOAc) extract of CMS (CMSEE) inhibited the proliferation and induced the differentiation of B16F1 cells [11]. To further address which compound was responsible for these effects, we isolated four compounds from

a chloroform-eluted fraction and identified their structures by spectral analysis (MS, ${ }^{1} \mathrm{H}$ NMR and ${ }^{13} \mathrm{C}$ NMR). These compounds were identified as p-hydroxycinnamaldehyde, coniferyl aldehyde, ligballinol and p-hydroxybenzaldehyde, which are all known to be abundant in CMS. The effects of these compounds on B16-F1 cell proliferation were then evaluated. The data showed that four compounds at $25 \mu \mathrm{M}$ inhibited the proliferation of B16-F1 cells (Fig. 1A, B). Both p-hydroxycinnamaldehyde

Fig. 1. Compounds isolated from CMS extracts and their effects on B16-F1 cells. (A) Compound structures and their effects on B16-F1 cell morphology. (B) Effects of CMS compounds on the number of B16-F1 cells, which was assessed as described in the Materials and Methods. Significant differences compared with the untreated group, $* \mathrm{P}<0.05$, ** $\mathrm{P}<0.01$. $(\mathrm{n}=3)$.
A

(a)

(b)

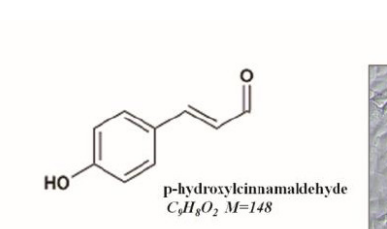

(c)
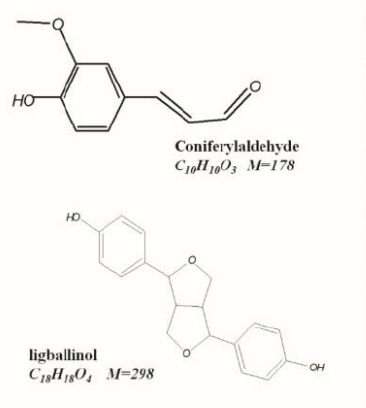

(d)
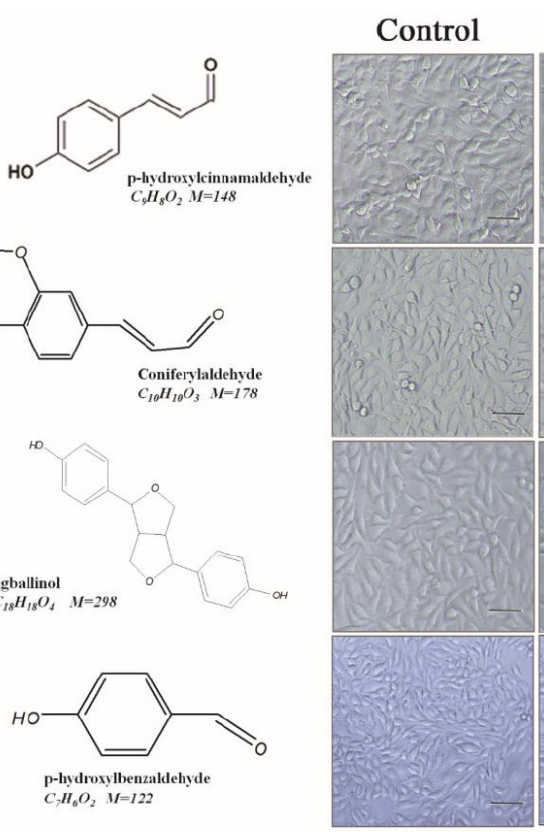

$25 \mu \mathrm{M}$

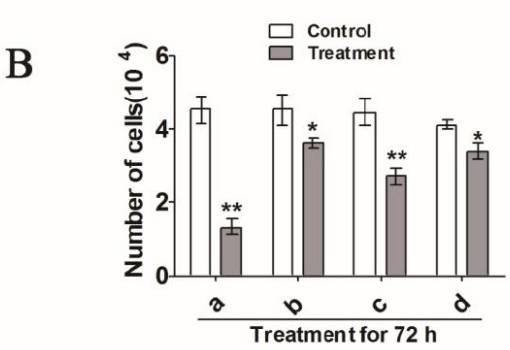

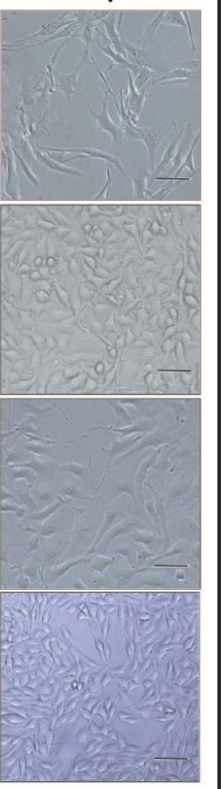


Fig. 2. Effects of CMSP on the morphology and viability of B16-F1 cells. (A) Effects of CMSP (10 $-40 \mu \mathrm{M}$ ) on the viability of B16-F1 cells, as detected by MTS assay. Significant differences compared with the untreated group, * $\mathrm{P}<0.05$, ** $\mathrm{P}<$ 0.01 , ( $n=3)$. (B) Effects of CMSP and forskolin on the morphology and cell number of B16-F1 cell cultures. Significant differences compared with the untreated groups, ${ }^{* *} \mathrm{P}$ $<0.01$, $(\mathrm{n}=3)$. (C) Effects of CMSP on the morphology and cell number of the normal melanocytic cell line HEM- $\alpha$.

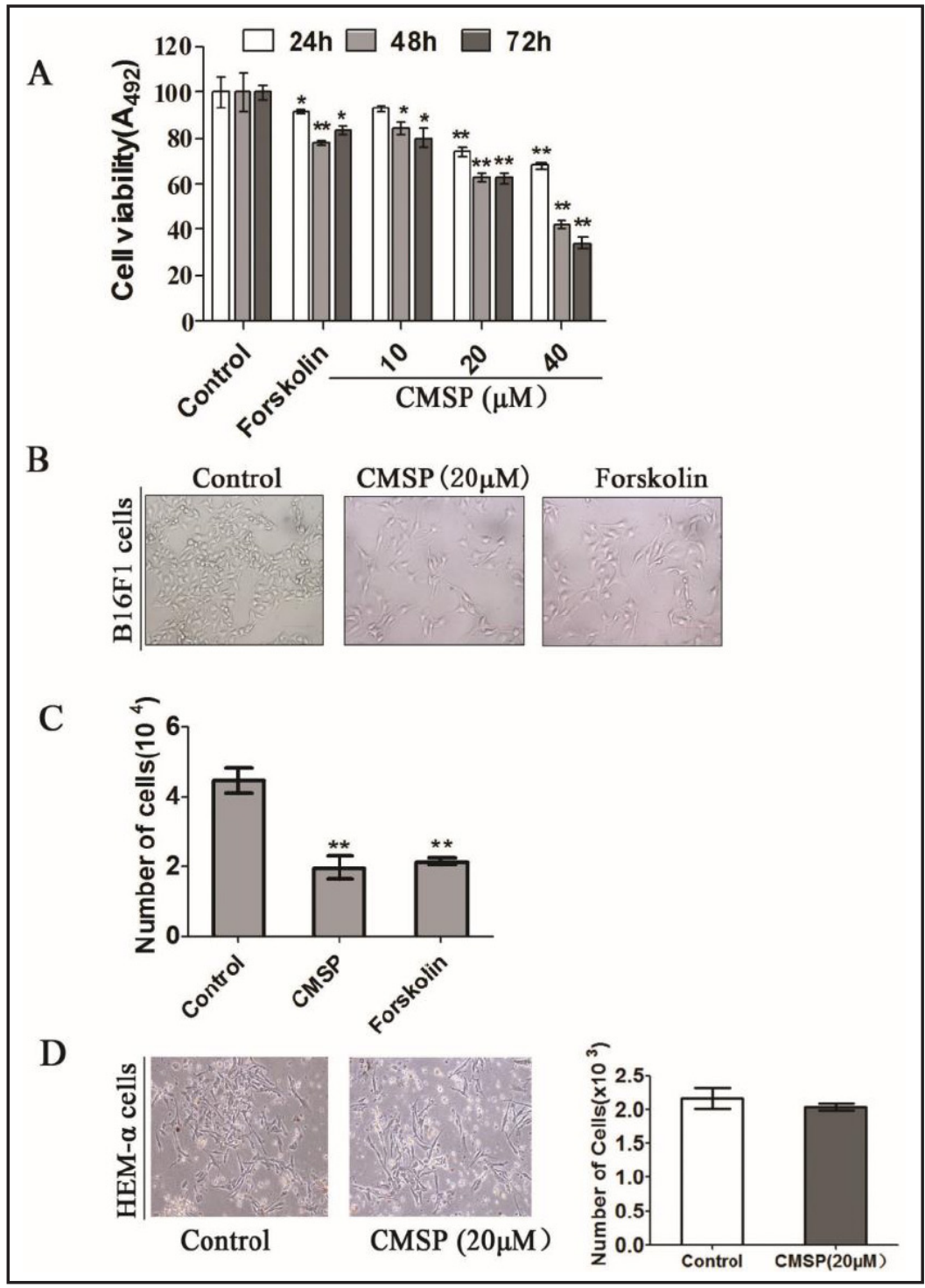

(CMSP) and ligballinol also induced morphological changes in B16-F1 cells analogous to those observed with CMSEE treatment. The concentrations of CMSP and ligballinol that induced differentiation in $50 \%$ of the cells were $4.23 \pm 0.32$ and $25.41 \pm 1.47 \mu \mathrm{M}$, respectively. This indicates that CMSP may be the most potent known chemical inducer of B16F1 cell differentiation. Therefore, we further explored the function and the underlying mechanism of this compound.

Growth arrest of melanoma B16-F1 cells by CMSP

To further evaluate the effect of CMSP on B16-F1 cell proliferation, the cells were exposed to different concentrations of $\operatorname{CMSP}(10,20$ or $40 \mu \mathrm{M})$ for 24,48 or $72 \mathrm{~h}$. As shown in Fig. 2A, B16-F1 cell proliferation was inhibited by CMSP in a dose- and time-dependent manner, whereas treatment with $0.01 \%$ DMSO had no effect. The morphological changes in the cells that were treated with CMSP were analogous to those induced by forskolin, which is a known inducer of B16-F1 differentiation [7]. Moreover, the number of cells in the cultures that were treated with forskolin or CMSP was also significantly decreased (Fig. $2 \mathrm{~B})$. In contrast, the number of cells and the morphology of normal melanocytic HEM- $\alpha$ cells were not changed after treatment with $20 \mu \mathrm{M}$ CMSP (Fig. 2C). This result suggests that CMSP specifically targets malignant cells and that it exerts no effect on normal melanocytic cells.

\section{KARGER}




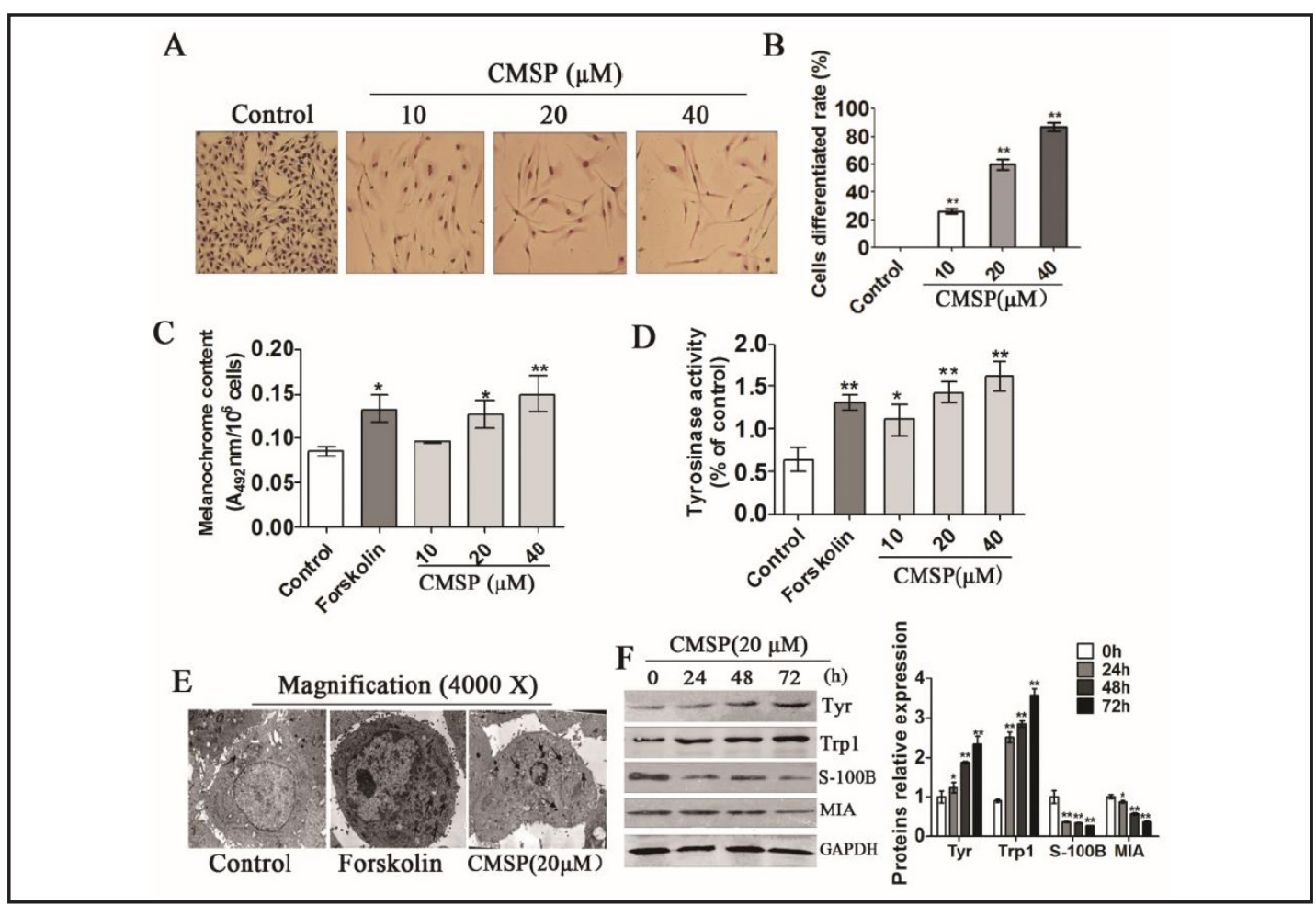

Fig. 3. Changes in the characteristics of B16-F1 cells with CMSP treatment. (A) Morphological changes and the rate of differentiation after treatment with CMSP for $48 \mathrm{~h}$ were assessed by Giemsa staining. Significant differences compared with untreated cells, ${ }^{* *} \mathrm{P}<0.01$. Scale bars indicate $50 \mu \mathrm{m}$. (B and C) Effects of CMSP treatment on melanin production and tyrosinase activity, which were assessed as described in the Materials and Methods. Significant differences compared with untreated cells, ${ }^{*} \mathrm{P}<0.05$, ${ }^{* *} \mathrm{P}<0.01$, ( $\mathrm{n}=3$ ). (D) Effects of CMSP treatment on melanogenesis in B16-F1 cells, as assessed by electron microscopy. Scale bars indicate $1 \mu \mathrm{m}$. (E) Effects of CMSP treatment on the expression of proteins associated with tyrosinase activity and malignant markers of melanoma, as assessed by western blot. GAPDH served as a loading control, and the data were normalized to the levels in untreated B16-F1 cells. The numbers below the panels represent the normalized protein expression levels, $(n=3)$.

\section{CMSP induces the differentiation of B16-F1 cells}

To further investigate whether CMSP induces the differentiation of melanoma cells, the morphological changes in B16-F1 cells were observed after Giemsa staining. As shown in Fig. 3A, cells that were treated with 10-40 $\mu \mathrm{M}$ CMSP showed typical dendritelike cellular protrusions, and the proportion of such elongated cells was significantly increased as the concentration of CMSP increased. Melanogenesis is a principal element of melanoma cell differentiation [17], and thus, melanin content was measured to further verify differentiation induced by CMSP. As shown in Fig. 3B, the treatment of B16-F1 cells with 10,20 or $40 \mu \mathrm{M}$ CMSP for $48 \mathrm{~h}$ caused a significant increase in the melanin content compared with the untreated and $0.01 \%$ DMSO-treated groups. We also evaluated the effect of CMSP on the activity of tyrosinase, a key enzyme in melanin synthesis [18, 19]. As shown in Fig. 3C, tyrosinase activity was markedly enhanced in cells that were treated with CMSP. In addition, the increased melanogenesis observed in B16-F1 cells that were treated with 20 $\mu \mathrm{M}$ CMSP was also investigated by electron microscopy (Fig. 3D). Protein analysis showed that, as a result of CMSP treatment, the expression level of tyrosinase was higher, whereas the expression of the melanoma cell markers S-100B and MIA was lower compared with control cells (Fig. 3E). These results demonstrate that CMSP is able to induce B16-F1 cell differentiation. 
A
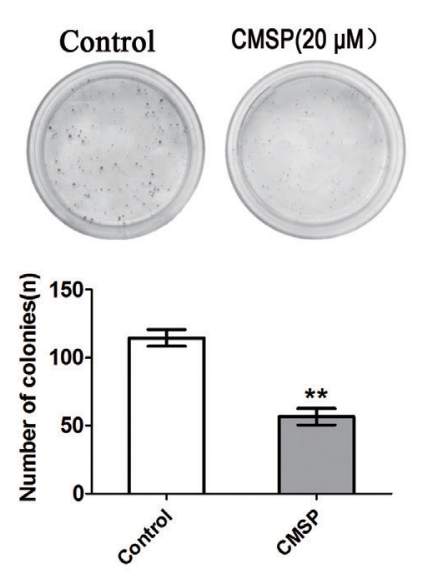

B

C

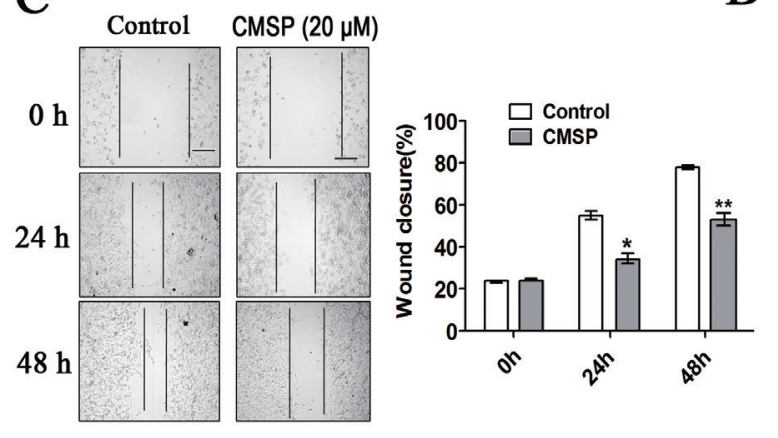

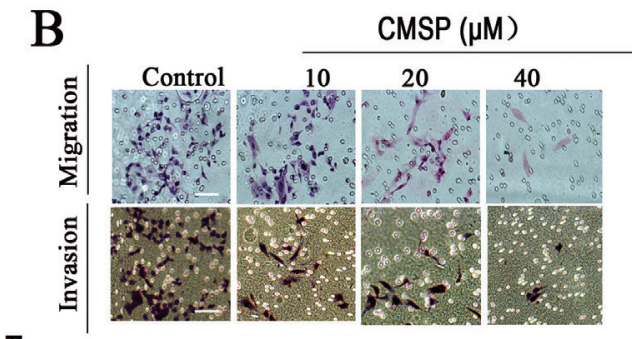

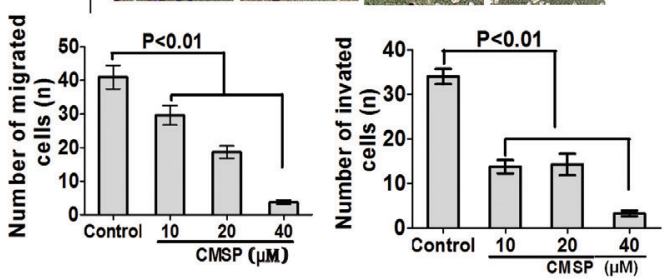

D

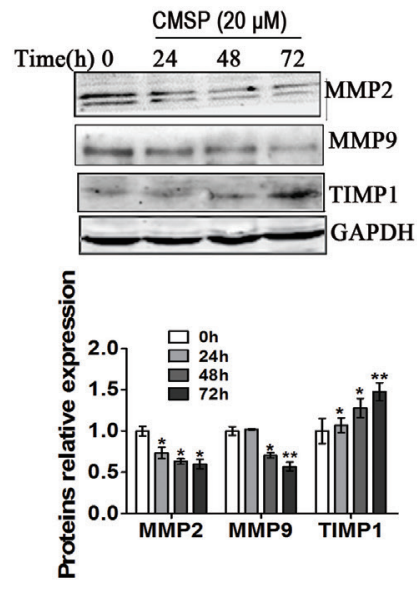

Fig. 4. Effects of CMSP treatment on colony formation, migration and invasiveness of B16-F1 cells. (A) Significant inhibition of cell colony formation was observed after treatment with CMSP $(20 \mu \mathrm{M})$ for $10 \mathrm{~d}$. The number of colonies was calculated $(n=5)$ and plotted on the histogram, as shown. Significant difference compared with the untreated group, ${ }^{* *} \mathrm{P}<0.01$. (B) The effects of CMSP $(20 \mu \mathrm{M})$ exposure for $24 \mathrm{~h}$ on migration (upper) and invasion (lower) were investigated by Transwell and Matrigel assays, respectively. The numbers of migrated and invading cells were calculated $(n=5)$. Significant differences compared with the untreated group, ${ }^{* *} \mathrm{P}<0.01$. Scale bars indicate $100 \mu \mathrm{m}$. (C) The effects of CMSP treatment for $24 \mathrm{~h}$ on B16-F1 cell mobility were investigated in an in vitro wound healing assay. Wounds were photographed and the degree of wound closure was temporally measured using AxioVison software. (D) The effects of CMSP treatment on the protein levels of MMP family members (MMP-2 and MMP-9) and TIMP1, as measured by western blot. GAPDH served as a loading control, and the data were normalized to the levels in untreated B16-F1 cells. The numbers below the panels represent the normalized protein expression levels $(n=3)$.

\section{CMSP inhibits colony formation, cell migration and metastasis of B16-F1 cells}

Colony formation and metastasis are two principal characteristics of malignant cells. We found that the number and size of the colonies were both decreased in B16-F1 cells that were treated with $20 \mu \mathrm{M}$ CMSP (Fig. 4A). A cell migration assay showed that the percentages of B16-F1 cells that migrated into Transwell filters after treatment with CMSP at concentrations of 10,20 or $40 \mu \mathrm{M}$ were $72.34 \%, 43.53 \%$ and $19.21 \%$ of the total cells loaded, respectively. This corresponded to the percentages of invading cells after treatment with 10, 20 of $40 \mu \mathrm{M}$ CMSP (43.04\%, 42.87\% and 12.32\%, respectively) (Fig. 4B). In the wound healing experiment, the number of B16-F1 cells that had migrated into the monolayer wound was decreased significantly after treatment with $20 \mu \mathrm{M}$ CMSP for 24 and $48 \mathrm{~h}$ (Fig. 


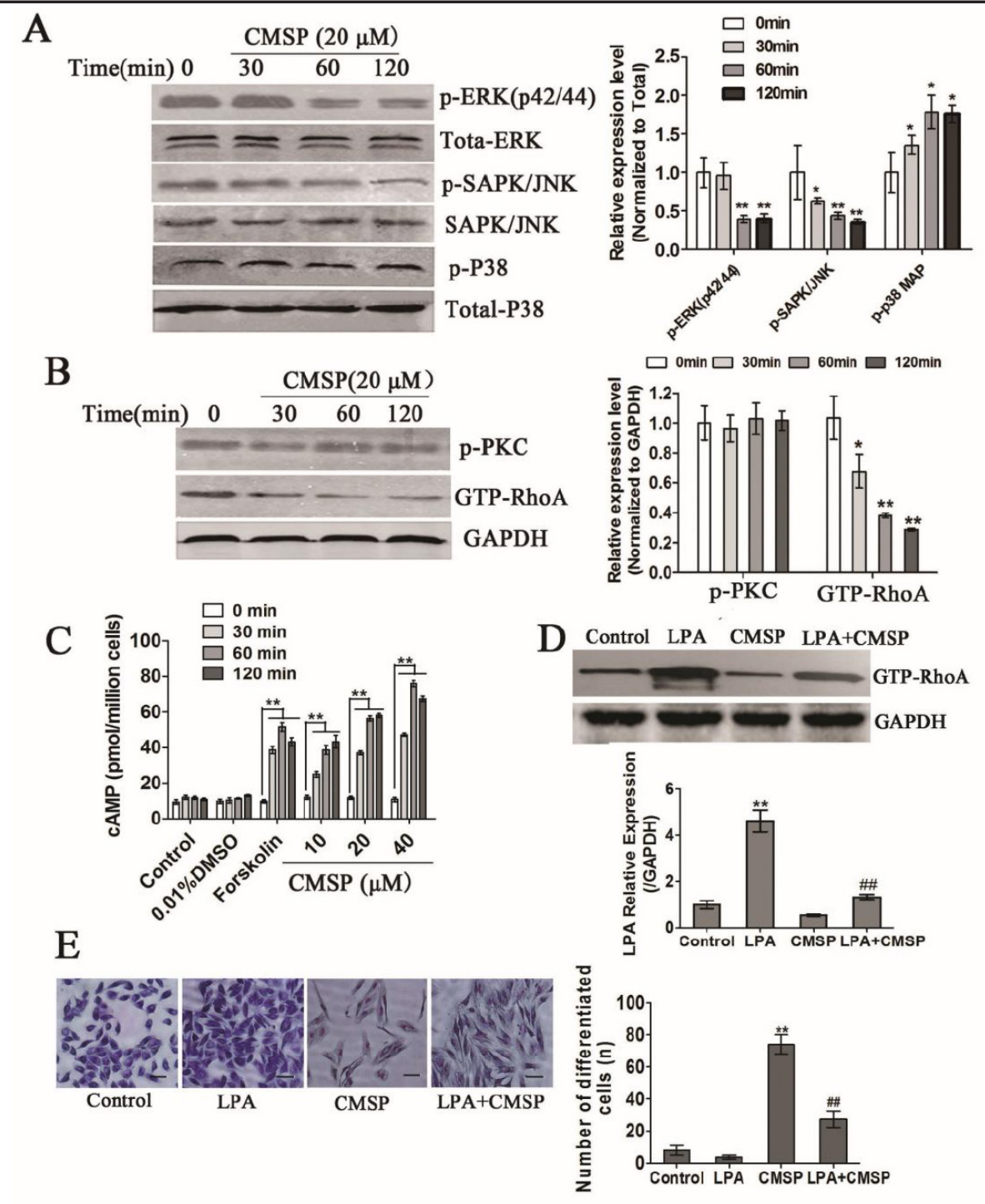

Fig. 5. Effects of CMSP treatment on MAPK activity in B16-F1 cells. (A) B16-F1 cells were treated with CMSP $(20 \mu \mathrm{M})$ for 30,60 or $120 \mathrm{~min}$. The levels of phosphorylated ERK, p38 and JNK kinase proteins in the cell lysates were assayed by western blot. GAPDH and total MAPK proteins were used as internal controls. The figures are representative examples of data from three independent experiments. Significant differences compared with the untreated group, ${ }^{*} \mathrm{P}<0.05$, ${ }^{* *} \mathrm{P}<0.01$, $(\mathrm{n}=3)$. (B) Phosphorylated PKC and GTP-RhoA proteins in cell lysates from B16-F1 cells that were treated with CMSP as described for (A), were assayed by western blot. GAPDH protein was used as an internal control. The figures are representative examples of data from three independent experiments. Significant differences compared with the untreated group, ${ }^{*} \mathrm{P}<$ $0.05,{ }^{* *} \mathrm{P}<0.01,(\mathrm{n}=3)$. (C) cAMP concentrations were determined in triplicate by ELISA. Each experiment was repeated three times and the data are shown here. (D) The expression of GTP-RhoA proteins in B16-F1 cells after treatment with LPA and (or) CMSP was assayed by western blot. GAPDH was used as an internal control $(n=3)$. (E) Morphological changes and the rate of differentiation of B16 cells were assessed by Giemsa staining, Significant differences compared with the control group, ${ }^{* *} \mathrm{P}<0.01$, and compared with the CMSP group, ${ }^{\# \#} \mathrm{P}<0.01$. Scale bars indicate $50 \mu \mathrm{m}(\mathrm{n}=3)$.

4C). The matrix metalloproteinase (MMP) family is essential for the metastasis of malignant cells. As expected, the expression of MMP-2 and MMP-9 was decreased, while that of the metalloproteinase inhibitor TIMP1 was increased in CMSP-treated B16-F1 cells (Fig. 4D). 


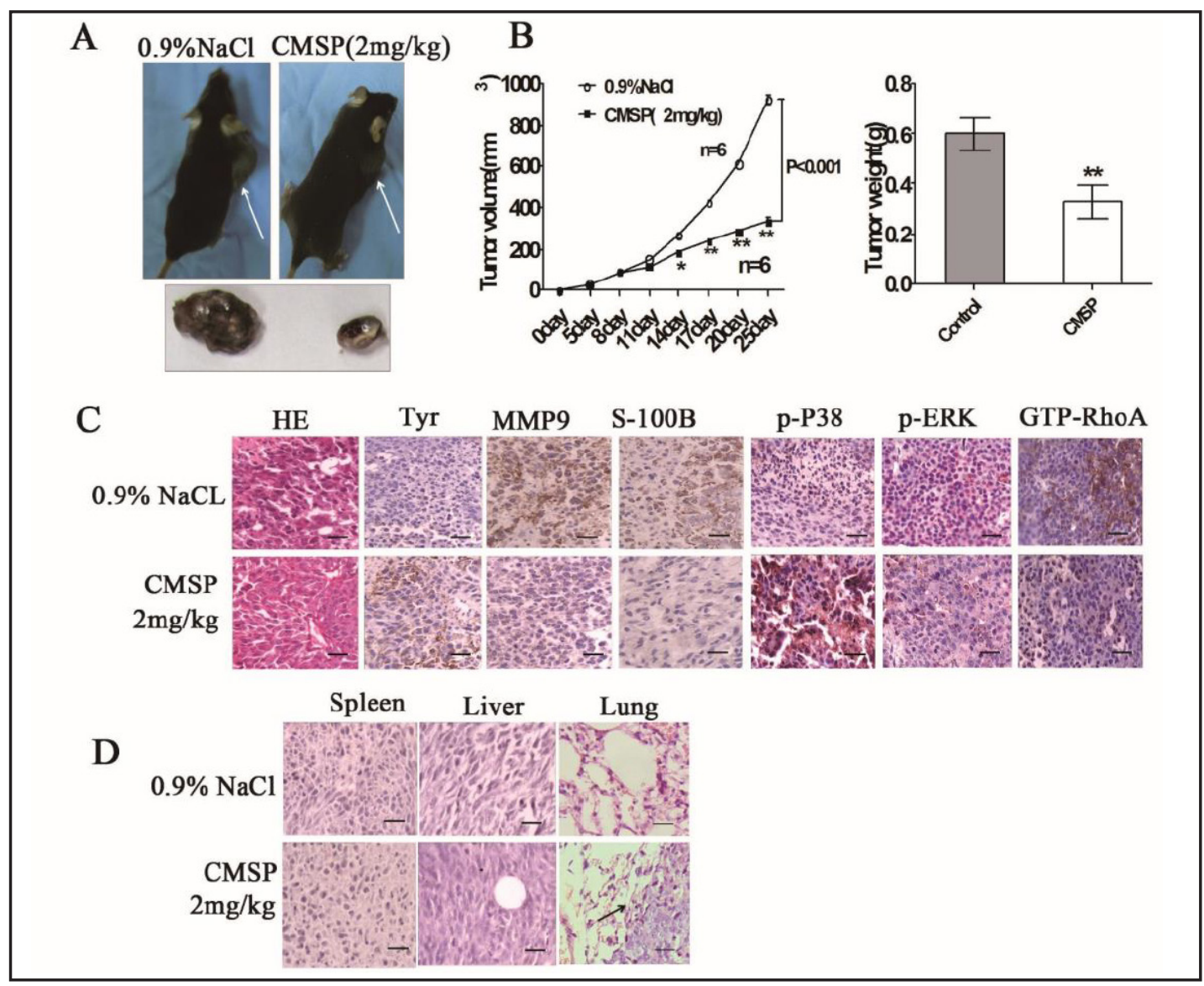

Fig. 6. Inhibition of B16-F1 cell growth and metastasis in vivo by treatment of mice with CMSP. (A-B) Experiments that involved the in vivo melanoma model were performed as described in the Materials and Methods. CMSP treatment inhibited the growth of tumors formed by B16-F1 cells in vivo. Left: Representative images of tumors formed in nude mice. Middle: Growth curves of the xenograft tumors. Left: Tumor weights were measured ( $n=6$ for each group) and are shown as means \pm SD. (C) Representative immunohistochemistry images show the expression levels of tyrosinase, MMP-9, S-100B, p-P38, p-ERK and GTP-RhoA in tumor tissues from mice treated with $0.9 \% \mathrm{NaCl}$ and from those treated with CMSP. Scale bars indicate 100 $\mu \mathrm{m}$. (D) Histological analysis of sections from the spleen, liver and lungs of mice treated with CMSP (2 mg/ $\mathrm{kg}$ ) and from untreated mice. Representative H\&E images are shown. Scale bars indicate $100 \mu \mathrm{m}$.

Overall, these results indicate that CMSP treatment attenuates the malignant phenotype of B16-F1 cells.

CMSP inhibits the activities of ERK and JNK but enhances $p 38$ signaling

To investigate the cellular pathways influenced by CMSP, its effects on MAPK signaling, which is known to be involved in the migration, invasiveness and differentiation of B16-F1 cells, were evaluated $[3,7]$. As shown in Fig. 5A, CMSP treatment significantly suppressed the activation of the ERK and JNK signaling pathways, while it enhanced the activation of the p38 pathway. Both the RhoA and PKC signaling pathways are upstream of the MAPK signaling pathway [20-22]. A western blotting assay showed that GTP-RhoA, but not PKC, was affected by the treatment of B16-F1 cells with CMSP (Fig. 5B). Furthermore, an ELISA assay for cAMP was used to elucidate the signaling pathway that mediates CMSP-induced B16-F1 cell differentiation. CMSP treatment (10-40 $\mu \mathrm{M})$ increased cAMP levels 2- to 6-fold above basal levels; cAMP levels reached a maximum in the $40 \mu \mathrm{M}$-treated group at $60 \mathrm{~min}$ (Fig. $5 \mathrm{C}$ ), which suggests that cAMP-RhoA signaling may be responsible for CMSP-induced changes in 


\section{Cellular Physiology Cell Physiol Biochem 2016;38:2247-2260 \begin{tabular}{l|l} 
and Biochemistry Published online: May 19, 2016 & $\begin{array}{l}\text { C 2016 S. Karger AG, Basel } \\
\text { www.karger.com/cpb }\end{array}$ \\
\hline
\end{tabular} \\ Zhao et al.: Melanoma Differentiation by $P$-Hydroxycinnamaldehyde}

MAPK. To further clarify the function of RhoA activity on CMSP-induced B16 differentiation, we used LPA, a GTP-RhoA agonist, in this experiment. The cells were pretreated with LPA (1 $\mu \mathrm{M}$ ) for $15 \mathrm{~min}$ followed by treatment with or without $40 \mu \mathrm{M}$ CMSP. The results are presented in Fig. 5 (D and E) and show that GTP-RhoA was significantly increased following treatment with LPA; the results also show that this compound was able to reverse the CMSP-induced differentiation of B16 cells. Taken together, these data indicate that CMSP might affect the RhoA-ERK/JNK axis, which regulates the differentiation of B16-F1 cells, but the mechanism of the CMSP-mediated changes in the p38 pathway remains unknown.

Effect of CMSP on the growth and differentiation of B16-F1 cells in vivo

A mouse melanoma model was used to evaluate the effects of CMSP on B16 cell growth in vivo. The volumes and weights of the tumors in mice that were treated with CMSP were markedly lower than those in control mice (Fig. 6A, B). Immunohistochemistry showed that, compared with the levels in control mice, tumors in CMSP-treated mice expressed higher levels of tyrosinase and lower levels of the melanoma markers S-100B, MIA-A and MMP-9. This staining pattern indicates that CMSP treatment induced the differentiation of the tumor cells. Moreover, tumors from mice that were given CMSP showed reduced p-ERK and GTPRhoA and increased p-p38 (Fig. 6 C). According to a histologic assessment, no cancer nodules were detected in the lungs from CMSP-treated mice, while several metastatic tumor nodules were seen in the control animals. In addition, both groups of mice showed no pathological changes in the liver or the spleen (Fig. 6 D).

\section{Discussion}

In the current study, we isolated several chemical compounds from CMS and identified CMSP as the most potent of these with respect to the induction of B16-F1 cell differentiation, which was characterized by decreased cell proliferation, increased dendrite-like outgrowth and enhanced melanin and tyrosinase activity. In our study, we demonstrated for the first time that CMS is able to induce the differentiation of melanoma cells, inhibit their proliferation and inhibit the metastasis of these cells.

The morphological correlates of dedifferentiation have been known for over a century, although an explanation of the mechanistic factors behind this process has been lacking [23]. In this study, we found that the growth of dendrite-like structures was exhibited by B16-F1 cells after treatment with 10-40 $\mu \mathrm{M}$ CMSP for 48 or $72 \mathrm{~h}$ (Fig. 1A, 2C and 3A). Additionally, increased melanogenesis and enhanced tyrosinase activity in CMSP-treated cells indicated the transition to a phenotype similar to that of melanocytes. This was confirmed by our observation of increased melanin corpuscles by electron microscopy. S-100B and MIA are widely used as biomarkers for melanoma [24-27]. In our study, the expression of both S-100B and MIA was significantly decreased in B16-F1 cells after treatment with CMSP, which suggested a mitigation of their malignant phenotype. Data from an in vivo melanoma model showed that in CMSP-treated mice, tumor growth was significantly slower compared with control animals; in addition, less metastasis was observed in CMSP-treated mice compared with controls. In agreement with this finding, a higher level of tyrosinase and lower levels of MIA, S-100B and MMP-9 proteins in tumors from CMSP-treated mice were found, which suggested a relatively benign phenotype. Moreover, no pathological changes were observed in the livers and spleens in both groups of mice (Fig. 6D), which suggested that CMSP, as administered, did not cause toxicity to either organ. To further explore the molecular mechanism of CMSP-induced B16-F1 cell differentiation, we analyzed the activities of the MAPK and Rho signaling pathways. MAPK-related proteins, such as ERK, c-JNK, p38 MAPK kinase or Erk5/BMK, play important roles in the differentiation of various cancer cells [28, 29] including melanoma cells [30]. In agreement with this result, the enhanced activity of p38 MAP and the decreased activity of ERK1/2 and JNK were investigated in CMSP-treated B16-F1 cells. GTPase-RhoA and PKC are known upstream activators of cellular MAPK pathways, and 


\section{Cellular Physiology Cell Physiol Biochem 2016;38:2247-2260 \begin{tabular}{l|l|l} 
DOI: 10.1159/000445580 & C $2016 \mathrm{~S}$. Karger AG, Basel
\end{tabular} \begin{tabular}{l|l} 
and Biochemistry Published online: May 19, 2016 & www.karger.com/cpb
\end{tabular} \\ Zhao et al.: Melanoma Differentiation by $P$-Hydroxycinnamaldehyde}

both of these proteins have been reported to regulate cancer cell differentiation and adhesion [31-34]. We found that treatment of B16-F1 cells with CMSP caused decreased levels of GTPRhoA but led to no changes in p-PKC. The inhibition of RhoA has been determined to be required for cAMP-induced differentiation of melanoma cells [35]. Therefore, we further studied the mechanism of CMSP by monitoring levels of the second messenger cAMP. We found increased levels of cAMP in cells that were treated with CMSP compared with control cells. These findings indicate that cAMP-RhoA might be a key factor that mediates CMSPinduced cancer cell differentiation, and additional studies should be conducted to illustrate the mechanism of CMSP-mediated changes in the cAMP-RhoA pathway.

In conclusion, our study provides the first insight into the phenomenon that p-hydroxycinnamaldehyde from CMS (CMSP) modulates the proliferation, metastasis and differentiation of B16-F1 cells. Additionally, we provide the first evidence that the suppression of RhoA, ERK, and JNK and that the promotion of the p38 signaling pathway mediate the differentiation of B16-F1 cells. Thus, CMSP might be a potential novel drug for the treatment of malignant melanoma.

\section{Abbreviations}

CMS (Cochinchina momordica seed); CMSP ( $p$-hydroxycinnamaldehyde isolated from CMS); $\alpha$-MSH (a-melanocyte-stimulating hormone); CMSEE (EtOAc extract of CMS); TEM (transmission electron microscopy); cAMP (cyclic adenosine monophosphate); MMP-2 (metalloproteinase 2); H\&E (hematoxylin-eosin staining); LPA (Lysophosphatidic acid); L-dopa (3, 4-dihydroxy-L-phenyl-alanine).

\section{Acknowledgments}

This study was supported by the fund of Hebei Province Science and Technology Plan Project (No.20120120) and by the Financial Department of Hebei province (No.20142065).

\section{Disclosure Statement}

The authors have declared that no conflict of interest exists.

\section{References}

1 Prignano F, Coronnello M, Pimpinelli N, Cappugi P, Mini E, Giannotti B: Immunophenotypical markers, ultrastructure and chemosensitivity profile of metastatic melanoma cells. Cancer Lett 2002;186:183-192.

2 Balch CM, Gershenwald JE, Soong SJ, Thompson JF, Atkins MB, Byrd DR, Buzaid AC, Cochran AJ, Coit DG, Ding S, Eggermont AM, Flaherty KT, Gimotty PA, Kirkwood JM, McMasters KM, Mihm MC, Jr., Morton DL, Ross MI, Sober AJ, Sondak VK: Final version of 2009 AJCC melanoma staging and classification. J Clin Oncol 2009;27:6199-6206.

3 Englaro W: Inhibition of the Mitogen-activated Protein Kinase Pathway Triggers B16 Melanoma Cell Differentiation. J Biol Chem 1998;273:9966-9970.

4 Scott G, Leopardi S: The cAMP Signaling Pathway has Opposing Effects on Rac and Rho in B16F10 Cells: Implications for Dendrite Formation in Melanocytic Cells. Pigment Cell Research 2003;16:139-148.

5 Colombo G, Sordi A, Turcatti F, Carlin A, Rossi C, Lonati C, Santambrogio L, Gatti S, Catania A: Change in gene expression profile induced by alpha-melanocyte stimulating hormone in a malignant mesothelioma cell line. Cell Mol Biol (Noisy-le-grand) 2006;52:69-74.

6 Hata K, Hori K, Murata J, Takahashi S: Remodeling of actin cytoskeleton in lupeol-induced B16 2F2 cell differentiation. J Biochem 2005;138:467-472. 


\section{Cellular Physiology Cell Physiol Biochem 2016;38:2247-2260 \begin{tabular}{l|l|l} 
DOI: 10.1159/000445580 & (C) 2016 S. Karger AG, Basel
\end{tabular} www.karger.com/cpb \\ Zhao et al.: Melanoma Differentiation by $P$-Hydroxycinnamaldehyde}

$7 \quad$ Hata K, Hori K, Takahashi S: Role of p38 MAPK in lupeol-induced B16 2F2 mouse melanoma cell differentiation. J Biochem 2003;134:441-445.

8 Xiao CW HSaRZ: Adjuvant effect of Extract of CochinchinaMomordica Seed on Foot-and-Mouth Disease Vaccination against Asia-I and O Type Strain in Guinea Pigs. Frontiers Agriculture China 2007;1:190-195.

9 Liu HR, Meng LY, Lin ZY, Shen Y, Yu YQ Zhu YZ: Cochinchina momordica seed extract induces apoptosis and cell cycle arrest in human gastric cancer cells via PARP and p53 signal pathways. Nutr Cancer 2012;64:1070-1077.

10 Kang JM, Kim N, Kim B, Kim JH, Lee BY, Park JH, Lee MK, Lee HS, Jang IJ, Kim JS, Jung HC, Song IS: Gastroprotective Action of Cochinchina Momordica Seed Extract Is Mediated by Activation of CGRP and Inhibition of cPLA(2)/5-LOX Pathway. Dig Dis Sci 2009;54:2549-2560.

11 Zhao L-M, Han L-N, Ren F-Z, Chen S-H, Liu L-H, Wang M-X, Sang M-X, Shan B-E: An Ester Extract of Cochinchina Momordica Seeds Induces Differentiation of Melanoma B16 F1 Cells via MAPKs Signaling. Asian Pac J Cancer Prev 2012;13:3795-3802.

12 Sánchez Mas J, Martínez-Esparza M, Bastida CM, Solano F, Peñafiel R, García-Borrón JC: Regulation of ornithine decarboxylase in B16 mouse melanoma cells: synergistic activation of melanogenesis by $\alpha \mathrm{MSH}$ and ornithine decarboxylase inhibition. Biochim Biophys Acta 2002;1542:57-65.

13 Yan Y, Chou GX, Hui W, Chu JH, Fong WF, Yu ZL: Effects of sesquiterpenes isolated from largehead atractylodes rhizome on growth, migration, and differentiation of B16 melanoma cells. Integr Cancer Ther 2011;10:92-100.

14 Zhao L, Yan X, Shi J, Ren F, Liu L, Sun S, Shan B: Ethanol extract of Forsythia suspensa root induces apoptosis of esophageal carcinoma cells via the mitochondrial apoptotic pathway. Mol Med Rep 2015;11:871-880.

15 Rodriguez G, Ross JA, Nagy ZS, Kirken RA: Forskolin-inducible cAMP pathway negatively regulates T-cell proliferation by uncoupling the interleukin-2 receptor complex. J Biol Chem 2013;288:7137-7146.

16 Zhao LM, Jia YL, Ma M, Duan YQ, Liu LH: Prevention effects of Schisandra polysaccharide on radiationinduced immune system dysfunction. Int J Biol Macromol 2015;76:63-69.

17 Hirata N, Naruto S, Ohguchi K, Akao Y, Nozawa Y, Iinuma M, Matsuda H: Mechanism of the melanogenesis stimulation activity of (-)-cubebin in murine B16 melanoma cells. Bioorg Med Chem 2007;15:4897-4902.

18 Ohguchi K, Tanaka T, Kido T, Baba K, Iinuma M, Matsumoto K, Akao Y, Nozawa Y: Effects of hydroxystilbene derivatives on tyrosinase activity. Biochem Biophys Res Commun 2003;307:861-863.

19 Huang CH, Lu SH, Chang CC, Thomas PA, Jayakumar T, Sheu JR: Hinokitiol, a tropolone derivative, inhibits mouse melanoma (B16-F10) cell migration and in vivo tumor formation. Eur J Pharmacol 2015;746:148157.

20 Jayakumar T, Chiu CC, Wang SH, Chou DS, Huang YK, Sheu JR: Anti-cancer effects of CME-1, a novel polysaccharide, purified from the mycelia of Cordyceps sinensis against B16-F10 melanoma cells. J Cancer Res Ther 2014;10:43-49.

21 Sanchez-Mir L, Soto T, Franco A, Madrid M, Viana RA, Vicente J, Gacto M, Perez P, Cansado J: Rho1 GTPase and PKC ortholog Pck1 are upstream activators of the cell integrity MAPK pathway in fission yeast. PLoS One 2014;9:e88020.

22 Muscella A, Vetrugno C, Calabriso N, Cossa LG, De Pascali SA, Fanizzi FP, Marsigliante S: [Pt(0,0'-acac) (gamma-acac)(DMS)] alters SH-SY5Y cell migration and invasion by the inhibition of $\mathrm{Na}+\mathrm{H}+$ exchanger isoform 1 occurring through a PKC-epsilon/ERK/mTOR Pathway. PLoS One 2014;9:e112186.

23 Jogi A, Vaapil M, Johansson M, Pahlman S: Cancer cell differentiation heterogeneity and aggressive behavior in solid tumors. Ups J Med Sci 2012;117:217-224.

24 Wevers KP, Kruijff S, Speijers MJ, Bastiaannet E, Muller Kobold AC, Hoekstra HJ: S-100B: a stronger prognostic biomarker than LDH in stage IIIB-C melanoma. Ann Surg Oncol 2013;20:2772-2779.

25 Kruijff S, Hoekstra HJ: The current status of S-100B as a biomarker in melanoma. Eur J Surg Oncol 2012;38:281-285.

26 Schmidt J, Bosserhoff AK: Processing of MIA protein during melanoma cell migration. Int J Cancer 2009;125:1587-1594.

27 J S: A study on drug ability of MIA as a promising approach for inhibition of metastasis. Int J Comput Biol Drug Des 2014;7:80-95. 


\section{Cellular Physiology Cell Physiol Biochem 2016;38:2247-2260 \begin{tabular}{ll|l} 
and Biochemistry & $\begin{array}{l}\text { DOI: 10.1159/000445580 } \\
\text { Published online: May 19, } 2016\end{array}$ & $\begin{array}{l}\text { O 2016 S. Karger AG, Basel } \\
\text { www.karger.com/cpb }\end{array}$ \\
\cline { 2 - 3 }
\end{tabular} \\ Zhao et al.: Melanoma Differentiation by $P$-Hydroxycinnamaldehyde}

28 Chang JS, Santhanam R, Trotta R, Neviani P, Eiring AM, Briercheck E, Ronchetti M, Roy DC, Calabretta B, Caligiuri MA, Perrotti D: High levels of the BCR/ABL oncoprotein are required for the MAPK-hnRNP-E2 dependent suppression of C/EBPalpha-driven myeloid differentiation. Blood 2007;110:994-1003.

29 Sundaramurthy P S GRS: Computational prediction and analysis of impact of the cross-talks between JNK and P38 kinase cascades. Bioinformation 2009;3:250-254.

30 Selimovic D, Hassan M, Haikel Y, Hengge UR: Taxol-induced mitochondrial stress in melanoma cells is mediated by activation of c-Jun N-terminal kinase (JNK) and p38 pathways via uncoupling protein 2. Cell Signal 2008;20:311-322.

31 Brumby AM, Goulding KR, Schlosser T, Loi S, Galea R, Khoo P, Bolden JE, Aigaki T, Humbert PO, Richardson HE: Identification of novel Ras-cooperating oncogenes in Drosophila melanogaster: a RhoGEF/Rho-family/ JNK pathway is a central driver of tumorigenesis. Genetics 2011;188:105-125.

32 Yen TL, Lu WJ, Lien LM, Thomas PA, Lee TY, Chiu HC, Sheu JR, Lin KH: Amarogentin, a secoiridoid glycoside, abrogates platelet activation through PLC gamma 2-PKC and MAPK pathways. Biomed Res Int 2014;2014:728019.

33 Rottmar M, Mhanna R, Guimond-Lischer S, Vogel V, Zenobi-Wong M, Maniura-Weber K: Interference with the contractile machinery of the fibroblastic chondrocyte cytoskeleton induces re-expression of the cartilage phenotype through involvement of PI3K, PKC and MAPKs. Experimental Cell Research 2014;320:175-187.

34 Liu D, Xiong R, Chen X, Li P, Ning Y, Peng Y, Zhao Y, Yang N, Zhou Y: The glucocorticoid dexamethasone inhibits U937 cell adhesion and neutrophil release via RhoA/ROCK1-dependent and independent pathways. Cell Physiol Biochem 2014;33:1654-1662.

35 Buscà R BC, Abbe P, Englaro W, Ishizaki T, Narumiya S, Boquet P, Ortonne JP, Ballotti R: Inhibition of Rho Is Required for cAMP-induced Melanoma Cell Differentiation. Mol Biol Cell 1998;9:1367-1378. 